\title{
CONCURSO APARENTE DE NORMAS E A CONSEQUENTE UNICIDADE DE REAÇÃO PUNITIVA DO ESTADO NO CRIME DE SONEGAÇÃO FISCAL MEDIANTE FRAUDE DOCUMENTAL
}

\author{
Patrícia Gondim Moreira Pereira ${ }^{44}$
}

Recebido em: 31/08/2018

Aprovado em: 29/09/2018

\begin{abstract}
RESUMO
Este artigo aborda a questão do concurso aparente de normas. Para tanto, será apontado seu conceito, seu fundamento, critérios utilizados para resolução dessa aparente pluralidade de tipos incriminadores concorrentes, sempre sob a perspectiva da proibição do bis in idem, ou seja, sobre a impossibilidade de dupla apenação contra a mesma pessoa pelos mesmos fatos. Será apontado como os tribunais superiores têm resolvido o conflito aparente de normas em sede de crime de sonegação fiscal mediante fraude documental. Objetiva-se, assim, demonstrar que sem embargo da conduta praticada pelo agente subsumir-se hipoteticamente a mais de um tipo penal, há a ocorrência de um único delito, devendo ser aplicada uma única pena.
\end{abstract}

Palavras-chave: Concurso aparente de normas. Sonegação fiscal e fraude documental. Ne bis in idem.

\section{INTRODUÇÃO}

Sob o aforismo ne bis in idem, se consagra um dos princípios informadores do direito punitivo, que, em sua concepção original, consistia na proibição de alguém ser punido duas vezes pelos mesmos fatos.

Com a complexidade das relações jurídico-sociais, o entendimento puramente processual do princípio do ne bis in idem se ampliou para além da (I) proibição do cúmulo de processos contra a mesma pessoa, incluindo também uma perspectiva material, consistente em proibições referentes (II) ao cúmulo de qualificações jurídicas decorrentes de uma única

\footnotetext{
44 Mestranda em Direito pela Pontifícia Universidade Católica de São Paulo - PUC/SP. Pós-graduada em Criminologia e em Direito Constitucional pela Universidade Federal do Rio Grande do Norte - UFRN. Juíza de Direito.
} 
conduta e (III) ao cúmulo de sanções, desde que fundados nos mesmos fatos e contra a mesma pessoa (LEULIER-FISCHER, 2005). ${ }^{45}$

Apesar de haver alguns questionamentos sobre a autonomia da função do princípio do ne bis in idem relacionada a inadmissibilidade do cúmulo de qualificações jurídicas (LEULIER-FISCHER, 2005) ${ }^{46}$, se considera relevante a análise dessa interdição, tanto como forma de ser garantida a proporcionalidade das sanções aplicadas, como pelo fato de alguns doutrinadores atribuírem à proibição do bis in idem status de princípio informativo da solução do concurso de normas (CARBONELL MATEU, 1995; JAKOBS, 1995; MANTOVANI, 2009; MIR PUIG, 1996; MORILLAS CUEVA, 2000; PRADO, 1999; QUINTERO OLIVARES, 2009; ZULGADÍA ESPINAR, 2004).

É que sobre uma mesma conduta poderá concorrer mais de um tipo penal, sendo cada vez mais frequente a ocorrência dessa sobreposição normativa, talvez por força da expansão de um direito penal nem sempre mínimo e racional, sendo comum o entrelaçamento entre condutas típicas, não apenas no Direito Penal, mas também nos pontos de interconexão entre o Direito Penal e o Direito Tributário Penal.

A propósito, se faz necessário buscar uma melhor compreensão sobre o conceito do concurso aparente de normas, seu fundamento e quais seriam os critérios a serem utilizados na resolução dessa aparente pluralidade de tipos incriminadores concorrentes.

Nesse breve ensaio, se pretende apresentar alguns questionamentos sobre tal temática, sob a perspectiva da proibição de dupla valoração - princípio do ne bis in idem -, voltando-se a reflexão para a seguinte situação: na hipótese de apresentação de documento falso perante a autoridade tributária para fins de redução da base de cálculo de tributo, tal conduta poderia ser sancionada cumulativamente como delitos de sonegação e falsidade (material ou ideológica)? Ou apenas constituiria crime de sonegação?

São essas as pautas que serão adiante contextualizadas, com o intuito de serem apresentadas ideias e argumentos que venham a contribuir com o debate sobre a impossibilidade de dupla apenação pelos mesmos fatos, como decorrência da incidência do concurso aparente de normas.

\section{CONCURSO APARENTE DE NORMAS: CONCEITO E FUNDAMENTO}

\footnotetext{
${ }^{45}$ LEULIER-FISCHER, Juliette. La règle ne bis in idem. 2005. 586 f. Tese (Doutorado em 2005) - Université Panthéon-Sorbonne (Paris I), Paris, 2005.

${ }^{46}$ LEULIER-FISCHER, Juliette. La règle ne bis in idem. 2005. 586 f. Tese (Doutorado em 2005) - Université Panthéon-Sorbonne (Paris I), Paris, 2005.
} 
Costuma-se definir o concurso aparente de normas quando parece incidir, em razão da prática de uma conduta, dois ou mais preceitos normativos, aplicando-se apenas uma das formulações legais ao caso concreto, cujo conteúdo abrange a totalidade de injusto de todos os tipos eventualmente concorrentes. Em outras palavras, "sempre que sobre um determinado comportamento [incidir], simultaneamente, mais de uma norma penal incriminadora, embora

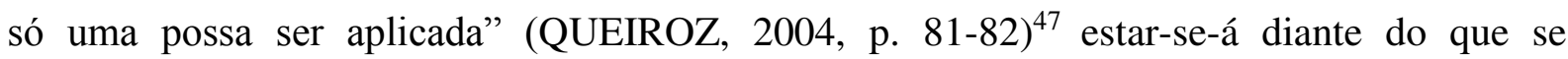
denomina concurso de leis, concurso de tipos ou de concurso aparente de normas.

Há na doutrina diversos termos para indicar esse conflito, tais como concurso de leis, concurso aparente de tipos, conflito de tipicidades, conflitos de tipos penais, colisão de leis penais, unidade de lei e unidade de crime. De qualquer forma, importante ser mencionada a diferença trazida por Andrei Zenkner Schmidt a respeito de conflito aparente de tipos penais e de conflito aparente de tipicidades.

No primeiro caso, o conflito trava-se abstratamente, tornando-se aparente porque, no plano do dever ser, na verdade inexistiu. Já no segundo caso, o conflito ocorre não no plano do dever ser, mas sim no plano do ser, e passa a ser aparente somente a partir de um critério de justiça eleito pelo legislador. Naquele, está situado o princípio da especialidade; neste, o princípio da consunção (SCHMIDT, 2001, p. 74). ${ }^{48}$

Como na doutrina brasileira a terminologia mais empregada é conflito aparente de normas, se adotou essa última nomenclatura.

A solução atribuída ao concurso aparente de normas, qual seja, a prevalência de um único preceito normativo, tem sido considerada por muitos doutrinadores uma das manifestações ou consequência jurídica do princípio do ne bis in idem, pela qual se impediria a imposição de sanções decorrentes da apreciação ou valoração repetida de um mesmo fato $(\mathrm{JAKOBS}, 1995)^{49}$. E mesmo para aqueles doutrinadores que questionam o fundamento do concurso aparente de normas como decorrente do espectro de proteção do ne bis in idem, pois entendem que, no caso da consunção, deveria ser o princípio da proporcionalidade, se entende que não há razão para essa dicotomia, haja vista que a proporcionalidade também informa o ne bis in idem em sua dimensão material ou substancial - proibição do cúmulo de sanções mais de uma vez pelos mesmos fatos e contra a mesma pessoa.

\footnotetext{
${ }^{47}$ QUEIROZ, Paulo. Direito Penal: parte geral. 5. ed. Rio de Janeiro: Lumen Juris, 2004, p. 81-82.

48 SCHMIDT, Andrei Zenkner. Concurso aparente de normas penais. Revista Brasileira de Ciências Criminais. Ano 9, n. 33, jan.-mar. 2001, p. 74.

49 JAKOBS, Günther. Derecho penal. Parte general. Trad. Joaquin Cuello Contreras e Jose Luis Serrano Gonzales de Murillo. Madrid: Marcial Pons, 1995.
} 
Com efeito, um dos efeitos do princípio do ne bis in idem é a proibição que sobre uma mesma ação recaia mais de um efeito fundamentador da responsabilidade criminal, impedindo-se, dessa forma, que por um mesmo conteúdo de injusto imponham-se diversas sanções (ESPINAR, 2004) $)^{50}$.

Costuma-se relacionar a solução principiológica de resolução do concurso aparente de normas como consequência lógica da proibição de castigar duas vezes o mesmo fato, destacando Mir Puig (1996) ${ }^{51}$ que, nessa antinomia, a aplicação conjunta de todos os preceitos legais violaria a proibição do bis in idem.

Diferente não é a posição de Luiz Regis Prado $(1999)^{52}$, ao esclarecer que o princípio de coerência sistemática e a máxima ne bis in idem, que veda punir duplamente o mesmo fato, fundamentam a solução aventada para o concurso aparente de normas.

Assim é que, evidenciando-se a concorrência de preceitos normativos sobre uma mesma conduta, nela incidirá apenas um dos tipos legais que, com maior precisão, subsumirse à situação em análise, compreendendo a totalidade do desvalor que caracteriza a atuação ilícita, excluindo-se, consequentemente, as demais normas.

\section{CONCURSO APARENTE DE NORMAS: REQUISITOS GERAIS E CRITÉRIOS RESOLUTIVOS}

O ordenamento jurídico brasileiro, até o presente momento, não indicou quais seriam os vetores para que houvesse a incidência do concurso aparente de normas, tampouco os critérios legais para a sua resolução.

A única manifestação de forma explícita no direito positivo sobre a matéria se deu no anteprojeto de Código Penal, de autoria de Nelson Hungria, apresentado em 1963, cuja proposta, inserida no Título I, dedicado a "aplicação da lei penal”, sob a rubrica "concurso aparente de normas", ${ }^{53}$ apesar de convertido em lei - Decreto-lei $\mathrm{n}^{\circ} 1.004$ - não chegou a entrar em vigor, em razão da suspensão por leis protelatórias.

\footnotetext{
${ }^{50}$ ESPINAR, José M. Zulgadía. et. al. Derecho penal. Parte general. 2. ed. Valencia: Tirant lo Blanch, 2004.

${ }^{51}$ MIR PUIG, Santiago. Derecho penal. Parte general. 4. ed. Barcelona: Arazandi, 1996.

52 PRADO, Luiz Regis. Curso de direito penal brasileiro. Parte geral. São Paulo: Revista dos Tribunais, 1999.

53 “Art. 5 . Quando a um mesmo fato podem ser aplicadas duas ou mais normas penais, atende-se ao seguinte, a fim de que só uma pena seja imposta:

a) a norma especial exclui a norma geral;

b) a norma relativa ao crime que passa a ser elemento constitutivo ou qualificado de outro é excluída pela norma atinente a este;
} 
Com isso, ficou reservado para a doutrina a solução da aparente incidência de mais de um preceito sancionador sobre um mesmo fato, pois como o legislador não falou, caberia, então, a filosofia resolver a matéria (GRECO, 2009) ${ }^{54}$.

Questão bastante discutida é se a identidade de fato deveria ser critério decisivo para o reconhecimento do concurso aparente de normas ou, se ao contrário, também permitir-se-ia a pluralidade de condutas ou a ocorrência de várias ações nas hipóteses dessa forma de concurso impróprio.

Para a determinação da noção de ação da teoria do concurso, a doutrina tem preferido utilizar dois conceitos para proceder a distinção entre a unidade e a pluralidade de ações: ação naturalística, que seria decorrente da ação em sentido natural, e a unidade naturalística de ação (TAVARES, 2009, p. 509-510) ${ }^{55}$.

Porém, como observado por Zaffaroni, Slokar e Alagia, "o certo é que o pretendido conceito de unidade pela natural concepção de vida tem sido uma fórmula vazia, que restou vazia de conteúdo", até porque não tem sido utilizada em um único sentido, mas sim em sentidos distintos, "o que a tornou praticamente inútil" a distinção entre a unidade e a pluralidade de ações (ZAFFARONI, ALAGIA, SLOKAR, 2002, p. 465) ${ }^{56}$.

Para Juarez Cirino dos Santos (2010, p. 399) ${ }^{57}$, “a fórmula adequada estaria na fusão dos conceitos de ação e de tipo legal, integrados na unidade do conceito de tipo de injusto”. E na construção do conceito de tipo de injusto, os elementos essenciais seriam a correlação entre seu "conteúdo determinante", evidenciado pela definição do que se entende como ação, e a sua "forma determinada", consistente na descrição do tipo legal.

De acordo com essa orientação, existiria unidade de tipo de injusto:

(a) em tipos legais divisíveis em pluralidade de atos, (b) em tipos legais que pressupõem pluralidade de atos, como o estupro (violência e conjunção carnal) e o roubo (violência de subtração), (c) em tipos legais de duração, caracterizados pela criação ou manutenção de situações antijurídicas, como violação de domicílio ou dirigir veículo automotor em via pública sem habilitação ou em estado de embriaguez etc.; por outro lado, existe também unidade de tipo de injusto em

c) a norma incriminadora de um fato que é meio necessário ou normal fase de preparação ou execução de outro crime é excluída pela norma a este relativa.

Parágrafo único. A norma penal que prevê vários fatos, alternativamente, como modalidades de um mesmo crime, só é aplicável uma vez, ainda quando os ditos fatos são praticados, pelo mesmo agente, sucessivamente".

54 GRECO, Luis. Dolo sem vontade. In: RAPOSO, João António; ALVES, João Lopes; MENDES, Paulo de Sousa. et. al. (Org.). Liber Amicorum de José de Sousa e Brito em comemoração do $\mathbf{7 0}^{\circ}$ aniversário: Estudos de Direito e Filosofia. Coimbra: Almedina, 2009.

55 TAVARES, Juarez. Teoria do crime culposo. 3. ed. Rio de Janeiro: Lumen Juris, 2009, p. 509-510.

${ }^{56}$ ZAFFARONI, Eugenio Raúl; ALAGIA, Alejandro; SLOKAR, Alejandro. Derecho penal: parte general. 2. ed. Buenos Aires: Ediar, 2002, p. 465.

${ }^{57}$ SANTOS, Juarez Cirino dos. Direito penal. Parte geral. 4. ed. Florianópolis: Conceito Editorial, 2010 , p. $399-400$ 
sentido amplo, (d) em situações de repetição da ação típica em rápida sequência temporal prevista no tipo (moeda falsa, rixa etc.) ou não prevista no tipo (remessa de escrito com várias injúrias, furto mediante pluralidade de ações de subtração etc.), desde que a repetição constitua simples aumento quantitativo do tipo de injusto mas independente da natureza do bem jurídico, podendo atingir bens jurídicos personalíssimos de diferentes portadores, assim como, finalmente, (e) em situações de contínua realização da ação típica por atos sequenciais de aproximação progressiva do resultado, como o tráfico de drogas, por exemplo (SANTOS, 2010, p. 399-400).

Portanto, unidade de ação, ou a unidade de tipo de injusto, utilizando-se a denominação utilizada por Juarez Cirino dos Santos (2010), pode se dar num só ato ou fato, manifestado por uma única resolução de vontade, ou numa cadeia de atos ou fatos vinculados numa unidade jurídica.

Por isso é que não se há como se entender que o fator decisivo na identificação do concurso aparente de normas seja a prática de uma única conduta ou de mais de uma conduta, devendo ser considerado o número de infrações, ao final, imputadas como o critério indispensável para seu reconhecimento. È que o essencial, quando da incidência do concurso aparente de normas, é que a imputação oferecida contra o agente se circunscreva a uma única infração, a um único tipo penal, que expresse todo o conteúdo do injusto do que foi realizado. Pensar de outra forma seria, verbi gratia, deixar de reconhecer a aplicação de apenas uma norma incriminadora nos casos de pós-fatos e antefatos impuníveis, onde, apesar da ocorrência de mais de uma ação, se trata de uma variante do princípio da consunção e, consequentemente, uma espécie de concurso aparente de normas, como se verá adiante.

Por todos esses argumentos, se espera ter justificado o porquê da escolha em não correlacionar a unidade de ação ou pluralidade de ações como critério determinante para o reconhecimento do concurso aparente de normas.

O mais importante é que o preceito prevalente contemple de modo total o desvalor que o ordenamento jurídico atribui a uma determinada conduta, como também a eventual pluralidade de condutas, a despeito da incidência sobre esse fato ou sobre esses fatos de normas penais concorrentes. Isso porque o ilícito principal deve traduzir ou esgotar o sentido e os efeitos das normas penais que concorrem aparentemente, representando "uma valoração autônoma e integral do conteúdo do injusto, sob pena de violação da proibição jurídicoconstitucional de que ninguém deverá ser sancionado duas vezes pelos mesmos fatos (DIAS, 2007, p. 1018) ${ }^{58}$.

Uma outra imprecisão sobre os pressupostos do concurso aparente de normas diz respeito a necessidade ou não de haver identidade do bem jurídico dos tipos confluentes. $\mathrm{O}$

\footnotetext{
${ }^{58}$ DIAS, Jorge Figueiredo. Direito Penal: parte geral. Tomo I. São Paulo: Revista dos Tribunais, 2007, p. 1018.
} 
enfrentamento dessa problemática é desafiadora, iniciando-se pela conceituação do que seria bem jurídico, termo polissêmico com diversas definições a depender da teoria ou corrente que se adote. Aliada a essa problemática, não é raro a ocorrência de tipos penais que visam dar proteção a bens "formalmente poliédricos ou multifacetados" e que não necessariamente guardariam correspondência entre "o nome juris ou a topografia do crime" e os valores que efetivamente buscariam proteger (COSTA, 2012, p. 234) ${ }^{59}$

Para além dessas dificuldades, o decisivo na questão deveria ser o entendimento de que o interesse protegido não deveria ser exigido para o reconhecimento do concurso aparente de normas penais, podendo, todavia, ser levado em consideração apenas como critério indiciário ou de forma limitada ou indicativa, "dado que ofender um bem jurídico e realizar um tipo são correlativos" (COSTA, 2012, p. 234) $)^{60}$.

Como disse José Lobo Moutinho, a identidade do bem jurídico não deve ser critério decisivo ou pressuposto de operatividade do concurso aparente de normas, uma vez que "pode suceder que uma norma que aparentemente tutela um bem jurídico tutele ainda outros bens jurídicos ou, rectius, que aquilo que parece um bem jurídico simples, se mostre, afinal, um bem jurídico complexo ou multifacetado" (MOUTINHO, 2005, p. 875) ${ }^{61}$.

Resumindo, os pressupostos de operatividade que autorizariam o reconhecimento do concurso aparente de normas são os seguintes: (a) unidade de conteúdo de injusto (unidade normativa) que congregue ou sob a qual recaia a aparente incidência de várias leis penais (mais de um tipo penal) que, a despeito da (b) prática de um determinado recorte ou fragmento de fato ou atém mesmo de uma pluralidade de fatos, em obediência aos princípios de unidade e coerência da ordem jurídica, especialmente, o princípio do ne bis in idem, deve se circunscrever a (c) imputação de apenas uma unidade de delito (um único crime), ou seja, deverá prevalecer tão somente um dos preceitos normativos - considerado aquele que contenha toda a reprovação jurídico-social do fato-, excluindo-se a aplicação dos demais preceitos normativos concorrentes.

Adiante, serão apresentados os critérios de resolução do concurso aparente de normas, a fim de fornecer aportes para subsidiar a escolha do preceito normativo prevalente.

\subsection{Especialidade}

\footnotetext{
${ }^{59}$ COSTA, Pedro Jorge. A consunção no direito penal brasileiro. Porto Alegre: SAFE, 2012, p. 234.

${ }^{60}$ Idem.

${ }^{61}$ MOUTINHO, José Lobo. Da unidade à pluralidade dos crimes no direito penal português. Lisboa: Universidade Católica Editora, 2005, p. 875.
} 
Se há algo que a doutrina concorde quanto ao concurso aparente de normas é quanto ao reconhecimento do princípio da especialidade como critério de resolução dessa problemática (NICAS, 2000) ${ }^{62}$.

Pela especialidade - lex specialis derogat legi generali -, a norma especial afasta ou derroga a geral. A norma especial é aquela que contém todos os elementos típicos da norma geral e, ao menos, um elemento a mais, chamado especializante, de natureza objetiva, subjetiva ou normativa. Os elementos especializantes, quando comparados aos elementos do tipo geral, identificam-se como plus ou, até mesmo, como minus, em comparação ao tipo geral.

A relação de aparente antinomia da lei especial sobre a lei geral ocorre no plano do dever ser, por meio da comparação do modelo abstrato dos tipos legais concorrentes, o que implica a necessária prevalência da univocidade do princípio da especialidade. Em expressão utilizada por Andrei Zenkner Schmidt $(2001)^{63}$, na análise do processo argumentativo do princípio da especialidade, as premissas que devem ser utilizadas são verdadeiro ou falso e não justo ou injusto.

Para alguns, a norma geral e a norma especial comportar-se-ia como círculos concêntricos, de modo que o âmbito da norma geral - o círculo maior - incluiria o âmbito da norma especial - o círculo menor (OLIVARES, 2009) ${ }^{64}$. Outros doutrinadores, ao contrário, enfatizam a relação de intensidade entre as normas, que levaria mais em consideração a inclusão do caso especial na amplitude do enunciado geral.

E talvez em razão dessa relação concêntrica ou compreensiva, também seja possível se aplicar às normas especiais o princípio da consunção, haja vista que o conteúdo mais amplo abrangerá necessariamente o menos amplo. Porém, o contrário não é verdadeiro, ou seja, nem toda norma consuntiva deve ser considerada uma norma especial (ALBERO, 1995) ${ }^{65}$.

Importante ser destacado, como visto acima, a desnecessidade da identidade do bem jurídico no concurso aparente de normas, sendo possível que haja, em matéria de especialidade, uma diferenciação entre os interesses ou valores protegidos. É que, por exaurir o conteúdo de injusto da conduta, o tipo especial predomina sobre o tipo geral.

\footnotetext{
62 NICÁS, Nuria Castelló. El concurso de normas penales. Granada: Comares, 2000.

63 SCHMIDT, Andrei Zenkner. Concurso aparente de normas penais. Revista Brasileira de Ciências Criminais. Ano 9, n. 33, jan.-mar. 2001.

${ }^{64}$ OLIVARES, Gonzalo Quintero. Parte general del derecho penal. Con la colaboración de Fermín Morales Prats. 3. ed. Barcelona: Arazandi, 2009.

65 ALBERO, Ramón García. "Non bis in idem” material y concurso de leyes penales. Barcelona: Cedecs Editorial, 1995.
} 


\title{
3.2 Subsidiariedade
}

Por meio da aplicação do aforismo lex primaria derogat legi subsidiariae, a incidência da norma principal prevaleceria sobre a norma subsidiária, inibindo-a, numa relação de mútua interferência entre os tipos legais. A norma subsidiária somente seria aplicada a uma determinada hipótese em não sendo aplicável a norma principal, ou seja, para a prevalência do tipo subordinante deve haver necessariamente a prévia realização do tipo subsidiário.

A “subsidiariedade significa que uma disposição penal só é aplicável secundariamente, isto é, só reivindica validade para o caso em que uma outra já não intervenha” (WESSELS, 1976, p. 180) ${ }^{66}$.

Como lembra Aníbal Bruno, o princípio da subsidiariedade tanto pode ser criado pela própria lei, por meio de expressões se o fato não constituir crime mais grave como também

\begin{abstract}
[...] da relação existente entre as normas, que se ocupam de fatos que podem ser tomados por graus diversos, de gravidade diferente, da violação do mesmo bem jurídico, sendo aplicáveis as normas relativas às formas menos graves só quando não caiba a aplicação da referente aos fatos de mais gravidade. A norma subsidiária é a menos grave, para qual recai o fato se não se ajusta tipicamente à norma principal. São subsidiárias, por exemplo, as disposições de leis que definem crimes de perigo em confronto com as referentes a crimes de dano, desde que seja o mesmo bem jurídico ameaçado ou violado (BRUNO, 2003, p. 169) ${ }^{67}$.
\end{abstract}

Por isso se diz que a subsidiariedade será expressa, nas situações decorrentes do comando legal, que condiciona taxativamente a aplicação de um tipo apenas na hipótese de não incidência de outro, considerado norma prevalente. E, por sua vez, a subsidiariedade será tácita, quando a escolha da norma considerada prevalente tiver sido deduzida do sentido dos tipos concorrentes, interpretado a partir do contexto normativo.

Nos termos do art. 15 do Estatuto do Desarmamento, por exemplo, hipótese de subsidiariedade explícita, constitui crime disparar arma de fogo em lugar habitado, desde que essa conduta não tenha como finalidade a prática de outro crime.

\footnotetext{
Note-se que esse outro crime pode ser maior ou menor (mais grave ou não). Não importa. O tipo penal do art. 15 só tem incidência quando o disparo é a finalidade última do agente. Se o disparo é efetuado para o fim de se cometer um homicídio ou uma lesão corporal, não tem incidência o art. 15 do Estatuto do Desarmamento. A regra de que o principal absorve o subsidiário, portanto, deve ser entendida da seguinte forma: ou o maior absorve o menor (CP, art. 132, v.g.) ou o fim absorve o meio (art. 15 citado) (GOMES, 2012, p. 369)
}

\footnotetext{
${ }^{66}$ WESSELS, Johannes. Direito penal (aspectos fundamentais). Trad. de Juarez Tavares. Porto Alegre: Fabris, 1976, p. 180.

${ }^{67}$ BRUNO, Aníbal. Direito penal. Parte geral. Tomo I. 5. ed. Rio de Janeiro: Forense, 2003, p. 169.

${ }^{68}$ GOMES, Luiz Flávio (coord.). Direito penal: fundamentos e limites do Direito penal. 3. ed. São Paulo: Revista dos Tribunais, 2012, p. 369.
} 
Quanto à subsidiariedade tácita, essa ocorre quando um delito inibido ou subordinado (delito menor) vier a integrar a descrição do modelo abstrato ou tipo legal de outro (mais grave), como, por exemplo, no caso de furto, que seria crime subsidiário do roubo. O roubo seria subsidiário quanto ao crime de latrocínio. Nesse caso, se fala de uma relação de espécie e espécie (e não de gênero e espécie, como se passa no princípio da especialidade), ao contrário do que ocorre na subsidiariedade expressa, em que a dependência se decide tendo como referência o delito de maior gravidade e outro de menor intensidade (GOMES, 2012) ${ }^{69}$.

Vê-se, então, que na subsidiariedade expressa é possível o estabelecimento de uma dupla correspondência, onde o crime maior absorve o crime menor ou crime-fim absorve o crime-meio, enquanto na subsidiariedade tácita somente seria estabelecida a relação de maiormenor.

É que no processo de imputação da relação de subsidiariedade tácita, o liame de entrecruzamento se organiza em uma escala de maior-menor grau de agressão aos valores tutelados pelas normas confluentes. Como exemplos: a tentativa é subsidiária em face da consumação, como o auxílio, o induzimento e a instigação são subsidiários em face da autoria. Os fatos típicos de dano prevalecem quanto aos de perigo e os dolosos quanto aos culposos.

Ainda no que se refere aos tipos subsidiários, se destaca a relação de interferência existente entre o conteúdo das normas dos tipos concorrentes. Diferentemente do elo concêntrico do princípio da especialidade, dada a relação de intensidade ou compreensão existente entre as normas confluentes, a solução do entrecruzamento de tipos concorrentes pelo princípio da subsidiariedade lembra a figura de dois círculos secantes, com interseção entre suas esferas de aplicação ou sobreposição parcial (FERREIRA, 1981) ${ }^{70}$.

\subsection{Consunção}

A consunção é representada pelo aforismo lex consumens derogat legi consumptae e corresponde a um princípio de difícil conceituação, tanto quanto aos seus requisitos, como em relação as distintas situações que pode abranger.

Para Francisco de Assis Toledo,

\footnotetext{
${ }^{69}$ GOMES, Luiz Flávio (coord.). Direito penal: fundamentos e limites do Direito penal. 3. ed. São Paulo: Revista dos Tribunais, 2012.

${ }^{70}$ FERREIRA, Manuel Cavaleiro de. Direito penal português. v. I. Lisboa: Verbo, 1981.
} 
Há, na lei penal, tipos penais mais abrangentes e tipos penais mais específicos que, por visarem à proteção de bens jurídicos diferentes, não se situam numa perfeita relação de gênero para espécie (especialidade), nem se colocam numa posição de maior ou menor grau de execução do crime (TOLEDO, 1994, p. 53) ${ }^{71}$.

Talvez a grande dificuldade na compreensão do princípio da consunção decorra do seu sentido axiológico, pois sua aplicação se dá quando um dos tipos penais concorrentes é suficiente para valorar completamente os demais tipos que estão em jogo, pela consunção (absorção) da proteção que as outras visam.

E diferentemente do que ocorre com a especialidade e a subsidiariedade, a análise inferencial sobre as normas concorrentes não se dá no plano abstrato ou normativo, e sim estrutural ou fenomenológico, obtendo-se a decisão quanto à norma prevalente pela interpretação dos fatos efetivamente realizados pelo agente e não pelo cotejo dos tipos concorrentes. Na estrutura da consunção, se leva em consideração especialmente a conexão temporal entre os eventos ou a existência de algum liame entre as condutas lesivas.

Além do mais, uma outra particularidade que tem contribuído para a imprecisão conceitual quanto à consunção é que a aplicação desse princípio na resolução do conflito aparente de normas seria recomendável na ausência de critérios mais específicos, como a especialidade e a subsidiariedade, tanto que há autores que entendem que o princípio da consunção seria desnecessário, haja vista que a sobreposição normativa de que trata já seria englobada pelo princípio da subsidiariedade (AISA, 2004, p. 180) ${ }^{72}$.

Porém, como referenciado por ocasião dos comentários a respeito da subsidiariedade (item 3.2), nos conflitos de normas solucionados por esse postulado, há estágios variados de lesão ou perigo de lesão ao bem jurídico, de forma que a resolução proposta, quanto à lei aplicável, não depende exclusivamente da maneira pela qual o fato imputado foi praticado, sendo conduzida pela interpretação do próprio texto legal, que permitirá a exclusão do tipo menos grave em face do tipo mais grave.

Já na estrutura da aparente conduta integrada pela consunção, o que não se pode esquecer é que a norma prevalente deve ser a que mais integre ou aproxime de forma conjunta a compreensão do injusto, de maneira a englobar a total valoração do conteúdo de injusto, tanto que a mera referência à gravidade da pena, por si só, não impediria o reconhecimento de eventual unidade normativa, citando-se, como exemplo, a possibilidade de absorção da falsidade pelo estelionato, nos termos da Súmula 17 do Superior Tribunal de Justiça.

\footnotetext{
${ }^{71}$ TOLEDO, Francisco de Assis. Princípios básicos de direito penal. 5. ed. São Paulo: Saraiva, 1994, p. 53.

72 AISA, Estrella Escuchuri. Teoría del concurso de leyes y de delitos: bases para una revisión crítica. Granada: Comares, 2004, p. 180.
} 
Destaca-se ainda que a consunção ocorre quando um fato "não está necessariamente compreendido em um outro" (WESSELS, 1976, p. 180) ${ }^{73}$, concorrendo, todavia, para o seu cometimento.

O conteúdo de injusto do tipo principal consome o conteúdo de injusto do tipo secundário porque o tipo consumido constitui meio regular (não necessário) de realização do tipo consumidor ou o tipo consumido não está em relação de necessidade lógica (como na especialidade ou na subsidiariedade), mas em relação de regularidade fenomenológica com o tipo consumidor (SANTOS, 2010, p. 414) ${ }^{74}$.

Entende-se, portanto, que na consunção, a despeito da divergência sobre o assunto, não haverá relação de meio e fim, em caráter de indispensabilidade ou por força de lei, no cometimento do tipo principal. Quando se fala em consunção, se deve considerar que os fatos que formam a respectiva unidade normativa não constituem etapa comum de realização de nenhum dos tipos concorrentes.

Há ainda algumas situações de aparente concurso de crimes que devem ser consideradas como unidades normativas por força do princípio da consunção, a despeito de serem constituídas por uma pluralidade de ações. A propósito, entendem Hans-Heinrich Jescheck e Thomas Weigend que

É possível que uma pluralidade de ações seja submetida a uma única sanção, tal como ocorre nos casos de antefato e pós-fato impuníveis (também chamados de comportamentos copunidos), ou mesmo nas hipóteses de consunção, delitos progressivos [...] etc (JESCHECK; WEIGEND, 2002, p. 762 e 790) ${ }^{75}$.

O antefato impunível ocorre quando o crime anterior é considerado ato preparatório ou executório para a prática do crime prevalente, principal finalidade do agente. Pós-fatos impuníveis são os fatos realizados posteriormente à consumação do crime principal, na mesma linha de desdobramento causal, constituindo mero exaurimento daquele. São também pós-fatos impuníveis aqueles que não causam nova lesão a bem jurídico, como ainda os que violam os mesmos interesses tutelados pela norma prevalente ou ainda aqueles que mantêm a mesma unidade final-teleológica do delito principal.

O crime progressivo, por sua vez, é aquele no qual o agente, objetivando alcançar o resultado pretendido, pratica um só fato que, dada a sua natureza intrínseca, contém outro menos grave, pelo que a realização do primeiro sempre pressupõe a do segundo. A norma

\footnotetext{
${ }^{73}$ WESSELS, Johannes. Direito penal (aspectos fundamentais). Trad. de Juarez Tavares. Porto Alegre: Fabris, 1976, p. 180.

${ }^{74}$ SANTOS, Juarez Cirino dos. Direito penal. Parte geral. 4. ed. Florianópolis: Conceito Editorial, 2010 , p. 414.

75 JESCHECK, Hans-Heinrich; WEIGEND, Thomas. Tratado de derecho penal; parte general. Traducción de Miguel Olmedo Cardenete. 5. ed. Granada: Comares Editorial, 2002, pp. 762 e 790.
} 
prevalente seria "um estágio mais avançado e grau mais intenso de ofensa ao bem jurídico tutelado penalmente, excluindo-se a aplicabilidade da norma penal subsidiária relacionada ao fato precedente" (MARINUCCI; DOLCINI, 2009, p. 435) ${ }^{76}$.

Já a progressão criminosa se dá quando o agente, inicialmente, tem a intenção de praticar delito de gravidade inferior e, no mesmo curso causal que integra a descrição de modelo abstrato de um tipo concorrente de gravidade maior, vem a praticar este último.

Nos casos de antefato e pós-fato impunível, há de ser aplicado o princípio da consunção, desde que não haja relação de necessariedade entre o fato menos específico ou crime absorvido e ou fato mais abrangente ou crime prevalente. Indica-se a mesma solução quanto à hipótese do crime progressivo.

Nos casos da progressão criminosa, no entanto, se entende que deverá ser aplicado o princípio da subsidiariedade. Isso porque, em sendo passagem necessária para de um tipo fundamental menos grave para outro de maior gravidade, o bem jurídico menos importante está compreendido no bem jurídico ofendido da conduta sucessiva da progressão criminosa.

Visto os princípios da especialidade, subsidiariedade e da consunção, com destaque para a posição da doutrina quanto à norma mais adequada ou prevalente quando presente um concurso aparente de normas penais, oportuno se faz agora analisar o entendimento da jurisprudência quanto ao assunto, haja vista que, como já mencionado, não há na legislação penal brasileira amparo adequado sobre o assunto.

E como o objetivo do presente artigo está mais voltado para a reflexão sobre a possibilidade de eventual violação do ne bis in idem pela incidência de mais de uma sanção pelos mesmos fatos, se propõe adiante examinar se o crime de sonegação fiscal por meio de apresentação de documento falso representaria um caso de concurso aparente de normas com consequente impedimento da vedação do excesso punitivo pela aplicação de mais de um preceito normativo ou sancionatório.

\section{A UNIDADE NORMATIVA DO CONCURSO APARENTE DE NORMAS E CONSEQUENTE UNICIDADE DE REAÇÃO PUNITIVA DO ESTADO: ANÁLISE DE CASO}

\footnotetext{
76 MARINUCCI, Giorgio; DOLCINI, Emilio. Manuale di diritto penale. Parte generale. 3. ed. Milano: Giuffrè, 2009, p. 435.
} 
No início deste artigo foi proposta uma indagação: “em havendo a apresentação de documento falso perante a autoridade tributária para fins de omissão, redução ou supressão do pagamento de tributo, tal conduta deverá ser caracterizada cumulativamente como sonegação fiscal e falsidade ou apenas tipificada como sonegação? "; "estar-se-ia diante de apenas uma única infração penal ou de um concurso de crimes? "

A jurisprudência do Superior Tribunal de Justiça firmou orientação sobre tal questionamento, no sentido de que o crime de falso, perpetrado mediante entrega de recibos falsos a Receita Federal, com o fim de justificar a supressão ou redução de tributo, desde que não ostente potencialidade lesiva para o cometimento de outros delitos, configurando mero exaurimento do crime de sonegação fiscal, deve ser por este absorvido.

A propósito, no julgamento do AgRg no REsp n $n^{\circ}$ 1.347.646/MG, Rel. Ministro JORGE MUSSI, julgado em 05/02/2013, DJe 15/02/2013, a $5^{\text {a }}$ Turma do Superior Tribunal de Justiça, por unanimidade, negou provimento ao agravo regimental, nos seguintes termos:

PENAL. SONEGAÇÃO FISCAL. FALSIDADE IDEOLÓGICA. USO DE DOCUMENTO FALSO. DECLARAÇÃO FALSA PRESTADA PARA REDUÇÃO DA BASE DE CÁLCULO DO IMPOSTO DE RENDA DA PESSOA FÍSICA. APRESENTAÇÃO DE RECIBOS FISIOTERAPÊUTICOS IDEOLOGICAMENTE FALSOS À AUTORIDADE FAZENDÁRIA. EXAURIMENTO DA CONDUTA ANTERIOR. DELITOS AUTÔNOMOS. INOCORRÊNCIA.

1. A declaração falsa inserida na Declaração de Ajuste Anual do Imposto de Renda da Pessoa Física nada mais é do que a representação da informação contida no documento ideologicamente falsificado, do qual se utiliza o agente para obter a redução ou supressão do referido tributo, circunstância que impede a incidência dos tipos penais previstos no artigo 299 e 304 do Código Penal, para que não ocorra o vedado bis in idem.

2. O fato do sujeito passivo da obrigação tributária apresentar o documento ideologicamente falsificado à autoridade fazendária, quando chamado a comprovar as declarações prestadas em momento anterior, configura mero exaurimento da conduta necessária para a configuração do delito de sonegação fiscal, já que desprovido, neste momento, de qualquer outra potencialidade lesiva que exija a aplicação autônoma do delito descrito no artigo 304 do Estatuto Repressor.

3. Agravo regimental a que se nega provimento. (Grifo acrescido). ${ }^{77}$

Nesse caso, o Ministério Público interpôs agravo regimental contra decisão monocrática que negou seguimento ao recurso especial manejado, para obter o recebimento da denúncia em desfavor dos agravados pela prática das infrações descritas nos arts. 304 e 299 do Código Penal, sob a alegação de que o uso de documentos falsos, no caso recibos fisioterapêuticos, para obter redução da base de cálculo do imposto de renda pessoa física, constituiria crime próprio e não meio necessário para a prática do delito fiscal previsto no art.

77 BRASIL. Superior Tribunal de Justiça. AgRg no REsp no $1.347 .646 / M G$, Rel. Ministro Jorge Mussi, QUINTA TURMA, julgado em 05/02/2013, DJe 15/02/2013. 
$1^{\circ}$, IV, da Lei 8.137/90, porquanto os recibos falsos teriam sido produzidos ou utilizados em momento posterior ao da consumação do crime tributário.

Entenderam os Ministros, entretanto, que o crime relativo ao documento ideologicamente falsificado, por ter sido praticado após a consumação da declaração falsa prestada ao Fisco, seria considerado mero exaurimento da fraude tributária e, portanto, por esta absorvida. Isso porque, pela aplicação do princípio da consunção, a conduta de uso de documento falso há de ser excluída pela conduta final (crime-fim), que seria a prática do crime de sonegação fiscal.

Como observado no caso em análise, os documentos questionados foram apresentados a Receita Federal com o fim de justificar despesas fisioterapêuticas e, mesmo tendo sido a posterior, o foram com o fim de facilitar ou encobrir declaração falsa, que buscava a efetivação do crime de sonegação fiscal. Assim, não se há de falar, nas circunstâncias indicadas, em crimes autônomos, mas em atos parcelares tendentes a obtenção de lesão tributária.

Vê-se, que, muito embora, em tese, fosse possível a utilização da declaração falsa para outros fins, o delineamento fático do caso demonstrou que essa suposta ação irradiou efeitos lesivos apenas contra a ordem tributária, havendo a potencialidade lesiva do falsum sido preordenada a praticar o crime de sonegação fiscal mediante redução ou supressão do valor devido.

Com efeito, quando o falso se exaure ou se limita à sonegação de tributos, sem mais potencialidade lesiva, deve ser por esse absorvido, como crime-fim, com afastamento de todas as demais normas concorrentes, sob pena de ofensa ao ne bis in idem. Se a fraude documental foi somente meio necessário para a consumação da sonegação fiscal, é dizer, crime-meio para a prática do delito contra a ordem tributária (crime-fim), deve ser absorvido por este último.

Como disse José Manuel Palma Herrera, no concurso aparente de normas, a causa explicativa para que o ato copunido não se castigue de maneira autônoma, mas somente por meio da consequência prevista pelo legislador para o fato principal é que o "seu conteúdo desvalorativo é captado pelo preceito que resulta aplicável ao fato principal". Não obstante o fato principal e o fato copunido estarem previstos em tipos diversos, esse é, "sem embargo, captado integralmente em seu desvalor pelo último preceito (PALMA HERRERA, 2004, p. 137), sendo suficiente para exaurir o conteúdo do injusto.

A Terceira Seção do Superior Tribunal de Justiça, em julgamento ocorrido em 26 de dezembro de 2014, adotou a tese da aplicação do princípio da consunção ou da absorção quando os crimes de uso de documento falso e falsidade ideológica - crimes meio - tiverem 
sido praticados para facilitar ou encobrir a falsa declaração, para assegurar a sonegação fiscal - crime fim, desde que os crimes meio não extrapolem os limites da incidência do crime fim $^{78}$.

Também merece ser mencionado que, a despeito dos crimes de falsidade e sonegação fiscal objetivarem a proteção de bens jurídicos diversos, quais sejam, a fé pública e a ordem tributária, respectivamente, nada obsta a aplicação da absorção ou consunção nesse contexto, havendo o Superior Tribunal de Justiça já se pronunciado no sentido de não ser obstáculo para a aplicação da consunção a proteção de bens jurídicos diversos ou a absorção de infração mais grave pela de menor gravidade (REsp 1.294.411-SP, Quinta Turma, DJe 3/2/2014) ${ }^{79}$.

Doutro modo, não é o entendimento do Supremo Tribunal Federal, que tem decidido, reiteradamente, que a falsidade (material ou ideológica, arts. 297, 298 e 299 do CP), enquanto meio empregado para a prática do crime de sonegação físcal (art. $1^{\circ}$, I a IV, da Lei $\mathrm{n}^{\circ}$ 8.137/90), deve ser absorvida por este, não havendo que se falar em concurso de crimes (material ou formal, arts. 69 e 70 do CP). Cite-se, à guisa de exemplos de incidência concreta do princípio da consunção em sede de delito tributário, o que restou decidido no $\mathrm{HC} \mathrm{n}^{\circ}$ 84.453/PB, $1^{\text {a }}$ Turma do $\mathrm{STF}^{80}$ ou no Inquérito 3.102/MG, Pleno do $\mathrm{STF}^{81}$.

\section{CONSIDERAÇÕES FINAIS}

No concurso aparente de normas, como expressa a própria nomenclatura, a despeito da prática de uma só conduta - ou até mesmo de uma pluralidade de fatos - e da subsunção simultânea, mesmo que hipoteticamente, a mais de uma adequação típica convergente, não se

\footnotetext{
${ }^{78} \mathbf{O}$ crime de sonegação fiscal absorve o de falsidade ideológica e o de uso de documento falso praticados posteriormente àquele unicamente para assegurar a evasão fiscal. Após evolução jurisprudencial, o STJ passou a considerar aplicável o princípio da consunção ou da absorção quando os crimes de uso de documento falso e falsidade ideológica - crimes meio - tiverem sido praticados para facilitar ou encobrir a falsa declaração, com vistas à efetivação do pretendido crime de sonegação fiscal - crime fim -, localizando-se na mesma linha de desdobramento causal de lesão ao bem jurídico, integrando, assim, o iter criminis do delito fim. Cabe ressalvar que, ainda que os crimes de uso de documento falso e falsidade ideológica sejam cometidos com o intuito de sonegar o tributo, a aplicação do princípio da consunção somente tem lugar nas hipóteses em que os crimes meio não extrapolem os limites da incidência do crime fim. Aplica-se, assim, mutatis mutandis, o comando da Súmula 17 do STJ (Quando o falso se exaure no estelionato, sem mais potencialidade lesiva, é por este absorvido). Precedentes citados: AgRg no REsp 1.366.714-MG, Quinta Turma, DJe 5/11/2013; AgRg no REsp 1.241.771SC, Sexta Turma, DJe 3/10/2013. ERESp 1.154.362-MG, 26/12/2014.

${ }^{79}$ BRASIL. Superior Tribunal de Justiça. REsp 1.294.411-SP, Rel. Ministra Laurita Vaz, QUINTA TURMA, julgado em 10/12/2013, DJe 03/02/2014.

${ }_{80}$ BRASIL Supremo Tribunal Federal. HC $\mathbf{n}^{\mathbf{0}}$ 84.453/PB, Rel. Ministro Sepúlveda Pertence, PRIMEIRA TURMA, julgado em 17/05/2005, DJe 10/06/2005, EMENT VOL-02195-02PP-00274.

${ }^{81}$ BRASIL. Supremo Tribunal Federal. Inquérito 3.102/MG, Rel. Ministro Gilmar Mendes, Tribunal Pleno, julgado em 25/04/2013, DJe 19/09/2013.
} 
há de imputar ao agente a responsabilidade por mais de um crime, devendo prevalecer apenas uma das tipicidades concorrentes, haja vista a incidência do princípio ne bis in idem, que impede a dupla punição pelo mesmo fato.

Em razão da multiplicidade de sentidos que o conceito de bem jurídico pode assumir, assim como pela dificuldade em precisar a distinção entre a unidade e a pluralidade de ações, no sentido de ação naturalística, que seria decorrente da ação em sentido natural, e a unidade naturalística de ação, o essencial no concurso aparente de normas é a aplicação de apenas uma das normas concorrentes - aquela que alcança e esgota a relevância do caso em toda sua extensão valorativa. É que, em obediência ao princípio do ne bis in idem, ninguém pode ser castigado duas vezes pelo mesmo fato.

Assim, sem embargo da conduta praticada pelo agente subsumir-se hipoteticamente a mais de um tipo penal, na verdade, há a ocorrência de delito único e, consequentemente, deverá ser aplicada pena única - a sanção correlata ao único crime imputado.

Por isso, pode-se concluir que quando o crime de falso é cometido única e exclusivamente para o fim de suprimir ou reduzir tributos deve ser absorvido pelo crime de sonegação fiscal, sendo irrelevante, para tanto, que a apresentação do documento falso perante a autoridade fazendária seja posterior à entrega da declaração de imposto de renda porque apenas materializa a informação falsa antes prestada.

Ademais, como a lesividade da conduta não transcendeu o crime fiscal, deve incidir, na espécie, com as devidas adaptações, a Súmula 17 do Superior Tribunal de Justiça, in verbis: "Quando o falso se exaure no estelionato, sem mais potencialidade lesiva, é por este absorvido", aplicando-se, portanto, o princípio da consunção ou da absorção.

\section{REFERÊNCIAS}

AISA, Estrella Escuchuri. Teoría del concurso de leyes y de delitos: bases para una revisión crítica. Granada: Comares, 2004.

ALBERO, Ramón García. "Non bis in idem" material y concurso de leyes penales. Barcelona: Cedecs Editorial, 1995.

BRASIL. Superior Tribunal de Justiça. AgRg no REsp no 1.347.646/MG, Rel. Ministro Jorge Mussi, QUINTA TURMA, julgado em 05/02/2013, DJe 15/02/2013. 
Superior Tribunal de Justiça. AgRg no REsp 1.366.714-MG, Rel. Ministra Laurita Vaz, QUINTA TURMA, julgado em 22/10/2013, DJe 05/11/2013.

Superior Tribunal de Justiça. AgRg no REsp 1.241.771-SC, Rel. Ministra Laurita Vaz, SEXTA TURMA, DJe 3/10/2013.

Superior Tribunal de Justiça. ERESp 1.154.362-MG, Rel. Min. Laurita Vaz, julgado em 26/2/2014.

Superior Tribunal de Justiça. REsp 1.294.411-SP, Rel. Ministra Laurita Vaz, QUINTA TURMA, julgado em 10/12/2013, DJe 03/02/2014.

. Supremo Tribunal Federal. HC no 84.453/PB, Rel. Ministro Sepúlveda Pertence, PRIMEIRA TURMA, julgado em 17/05/2005, DJe 10/06/2005, EMENT VOL-02195-02PP00274.

. Supremo Tribunal Federal. Inquérito 3.102/MG, Rel. Ministro Gilmar Mendes, Tribunal Pleno, julgado em 25/04/2013, DJe 19/09/2013.

BRUNO, Aníbal. Direito penal. Parte geral. Tomo I. 5. ed. Rio de Janeiro: Forense, 2003.

CONTRERAS, Joaquín Cuello. La frontera entre el concurso de leyes y el concurso ideal de delito. ADPCP, 1979.

COSTA, Pedro Jorge. A consunção no direito penal brasileiro. Porto Alegre: SAFE, 2012.

DIAS, Jorge Figueiredo. Direito Penal: parte geral. Tomo I. São Paulo: Revista dos Tribunais, 2007.

ESPINAR, José M. Zulgadía. et. al. Derecho penal. Parte general. 2. ed. Valencia: Tirant lo Blanch, 2004.

FERREIRA, Manuel Cavaleiro de. Direito penal português. v. I. Lisboa: Verbo, 1981.

GOMES, Luiz Flávio (coord.). Direito penal: fundamentos e limites do Direito penal. 3. ed. São Paulo: Revista dos Tribunais, 2012. 
GRECO, Luis. Dolo sem vontade. In: RAPOSO, João António; ALVES, João Lopes; MENDES, Paulo de Sousa. et. al. (Org.). Liber Amicorum de José de Sousa e Brito em comemoração do $\mathbf{7 0}^{\circ}$ aniversário: Estudos de Direito e Filosofia. Coimbra: Almedina, 2009.

JAKOBS, Günther. Derecho penal. Parte general. Trad. Joaquin Cuello Contreras e Jose Luis Serrano Gonzales de Murillo. Madrid: Marcial Pons, 1995.

JESCHECK, Hans-Heinrich; WEIGEND, Thomas. Tratado de derecho penal; parte general. Traducción de Miguel Olmedo Cardenete. 5. ed. Granada: Comares Editorial, 2002.

LEULIER-FISCHER, Juliette. La règle ne bis in idem. 2005. 586 f. Tese (Doutorado em 2005) - Université Panthéon-Sorbonne (Paris I), Paris, 2005.

MANTOVANI, Ferrando. Diritti penale. 6. ed. Padova: CEDAM, 2009.

MARINUCCI, Giorgio; DOLCINI, Emilio. Manuale di diritto penale. Parte generale. 3. ed. Milano: Giuffrè, 2009.

MATEU, Juan Carlos Carbonell. Derecho penal. Concepto y principios constitucionales. Valencia: Tirant lo Blanch, 1995.

MIR PUIG, Santiago. Derecho penal. Parte general. 4. ed. Barcelona: Arazandi, 1996.

MOUTINHO, José Lobo. Da unidade à pluralidade dos crimes no direito penal português. Lisboa: Universidade Católica Editora, 2005.

NICÁS, Nuria Castelló. El concurso de normas penales. Granada: Comares, 2000.

OLIVARES, Gonzalo Quintero. Parte general del derecho penal. Con la colaboración de Fermín Morales Prats. 3. ed. Barcelona: Arazandi, 2009.

PRADO, Luiz Regis. Curso de direito penal brasileiro. Parte geral. São Paulo: Revista dos Tribunais, 1999.

QUEIROZ, Paulo. Direito Penal: parte geral. 5. ed. Rio de Janeiro: Lumen Juris, 2004. 
SANTOS, Juarez Cirino dos. Direito penal. Parte geral. 4. ed. Florianópolis: Conceito Editorial, 2010.

SCHMIDT, Andrei Zenkner. Concurso aparente de normas penais. Revista Brasileira de Ciências Criminais. Ano 9, n. 33, jan.-mar. 2001.

TAVARES, Juarez. Teoria do crime culposo. 3. ed. Rio de Janeiro: Lumen Juris, 2009.

TOLEDO, Francisco de Assis. Princípios básicos de direito penal. 5. ed. São Paulo: Saraiva, 1994.

WESSELS, Johannes. Direito penal (aspectos fundamentais). Trad. de Juarez Tavares. Porto Alegre: Fabris, 1976.

ZAFFARONI, Eugenio Raúl; ALAGIA, Alejandro; SLOKAR, Alejandro. Derecho penal: parte general. 2. ed. Buenos Aires: Ediar, 2002.

\title{
COMPETITIVE APPROACH TO STANDARDS AND THE CONSEQUENT UNITY OF PUNITIVE REACTION OF THE STATE IN THE CRIME OF FISCAL SONGATION THROUGH DOCUMENTARY FRAUD
}

\begin{abstract}
This article addresses the issue of apparent competition for standards. In order to do so, it will be pointed out its concept, its basis, criteria used to solve this apparent plurality of incriminating competing types, always with the perspective of the prohibition of bis in idem, that is, the impossibility of double jeopardy against the same person for the same facts. It will be pointed out how the higher courts have resolved the apparent conflict of norms in the crime of tax evasion by documentary fraud. It is therefore intended to demonstrate that, although the conduct practiced by the agent subsumes hypothetically more than one criminal type, there is a single offense, and a single penalty must be imposed.
\end{abstract}

Keywords: Apparent competition of rules. Tax evasion and document fraud. $\mathrm{Ne}$ bis in idem 